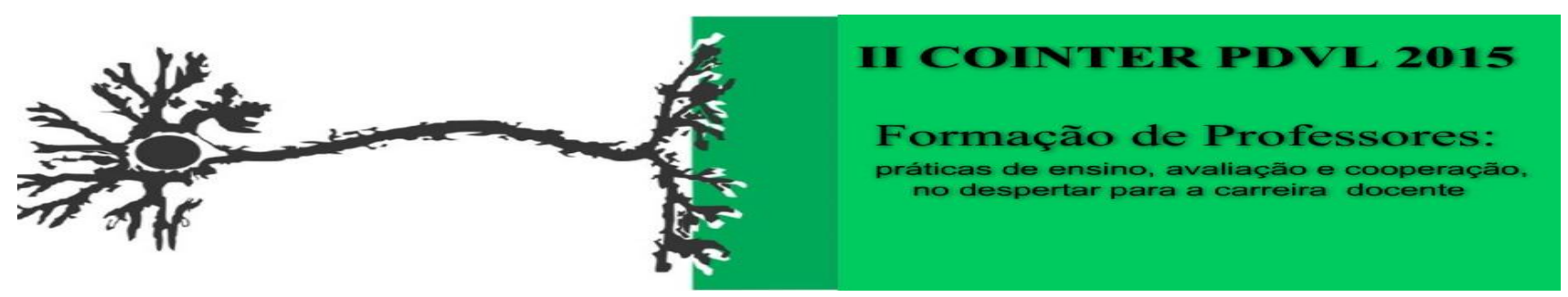

\title{
A ULITIZAÇÃO DA FEIRA DE CIÊNCIAS NO ENSINO DE FÍSICA: UMA ABORDAGEM HUMANÍSTICA COMO ESTRATÉGIA DE ENSINO E APRENDIZAGEM
}

\author{
Apresentação: Relato de Experiência \\ Julia Taisy do V. Bezerra $^{1}$; Andson Kelvin S. Rocha ${ }^{2}$; Marina Nunes de Oliveira ${ }^{3}$; George \\ N. D. Loula ${ }^{4}$
}

\section{Introdução}

O processo ensino-aprendizagem nas disciplinas de física é caracterizado por um grande nível de rejeição dos estudantes de Ensino Médio no Brasil. Dentre os motivos para que isso ocorra, existe um no qual tem um grande poder destrutivo: a falta de aplicabilidade dos conceitos. Uma feira de ciências vem como um arma para combater esse mal que ronda esta disciplina.

O desenvolvimento de uma feira de ciências, neste caso voltada para a disciplina de física, dá liberdade ao aluno para aprender da sua maneira e por meio de muitas ferramentas. Segundo Carl Rogers (1971), para outros educadores, dar liberdade a um grupo pode ser algo arriscado e perigoso de se fazer. Mas em contra partida propõem a experimentação de dar o grau de liberdade que eles podem, de maneira genuína e confortável, e observar os resultados.

O professor que ajuda o aluno a pensar por si próprio (auxiliando-o com autenticidade, confiando em sua habilidade) e, com carinho, conduzindo-o ao caminho da participação e independência é, realmente, um bom facilitador da aprendizagem. (Azevedo, 2005)

\section{Relato de Experiência}

Esta experiência mostra a elaboração e execução de uma feira de ciência e tecnologia ocorrida na Semana Nacional de Ciência e Tecnologia de 2015 com alunos de $2^{\text {o }}$ e $3^{\circ}$ anos do ensino médio da Escola de Referência em Ensino Médio Dr. Pacífico Rodrigues da Luz, no município de Petrolina-PE. A feira foi desenvolvida com a ajuda de 198 alunos, a professora de física e também supervisora do PIBID (Programa Institucional de Bolsa de Iniciação à Docência) e 4 alunos bolsistas do PIBID, sendo 2 deles autores desde relato.

\footnotetext{
${ }^{1}$ Estudante de Licenciatura em Física, IF Sertão Pernambucano, julia_taisy@hotmail.com

2 Estudante de Licenciatura em Física, IF Sertão Pernambucano, andsonkelvin@hotmail.com

${ }^{3}$ Estudante de Licenciatura em Física, IF Sertão Pernambucano, marina.mno@hotmail.com

${ }^{4}$ Professor EBTT, IF Sertão Pernambucano, george.loula@ifsertao-pe.edu.br
} 
Inicialmente a professora e nós, bolsistas, nos reunimos e discutimos o projeto. Optamos por deixar os alunos livres para escolherem os assuntos e experimentos que desejariam abordar. Além disso, decidimos que os grupos deveriam ser compostos por 10 alunos, ficando assim uma média de quatro grupos por sala.

Iniciada a corrida pela busca de experimentos a serem desenvolvidos, os bolsistas se prontificaram a ajudar os alunos, dando-lhes apoio técnico (materiais e construção) e explicações teóricas complementares. Complementares, pois, os alunos além de terem a liberdade de escolha dos assuntos e experimentos, também tinham que buscar explicações para os conceitos físicos e/ou químicos envolvidos.

Durante todo o processo de elaboração da feira de ciências o apoio do PIBID foi de grande importância. Além da parte financeira - disponibilizando materiais que a escola não pode comprar por conta de cortes do governo, também teve todo apoio pedagógico por parte dos bolsistas, supervisores e coordenadores.

\section{Considerações}

Seguindo a sugestão de Carl Rogers, observamos uma capacidade criativa destacável nos alunos participantes da feira de ciências, além disso, pudemos perceber um aprendizado decorrente da construção de experimentos aliado a uma fundamentação teórica que os mesmos tiveram que buscar para explicar os fenômenos físicos e químicos presentes nos mesmos.

\section{Referências}

AZEVEDO, Elisa. Concepção de Carl Rogers sobre aprendizagem. Disponível em <http://elisakerr.wordpress.com/concepcao-de-aprendizagem-de-carl-rogers/> Acesso em $25 \mathrm{de}$ Outubro de 2015.

ROGERS, Carl. Liberdade para aprender. Belo Horizonte: Interlivros, 1971.

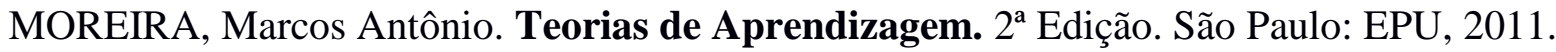

